\title{
Complement-dependent Lymphocytotoxicity Assay
}

National Cancer Institute

\section{Source}

National Cancer Institute. Complement-dependent Lymphocytotoxicity Assay. NCI

Thesaurus. Code C130171.

A method that detects the presence and reaction of alloantibodies to donor lymphocytes

in pre-transplant patients via the addition of complement proteins and lysis of the lymphocytes. 